\title{
THE STUDY OF THE RHEOLOGICAL BEHAVIOR AND THE OXIDATION STABILITY OF SOME COSMETIC EMULSIONS
}

\author{
ADELA MANEA ${ }^{a}$, ANDRA TAMAȘ $^{a^{*}}$, SABINA NIȚU ${ }^{a}$, DELIA PERJU ${ }^{a}$
}

\begin{abstract}
The paper presents the rheological behavior study of cosmetic emulsions as well as their oxidation stability. The influence of temperature and of the cooling rate was determined, as well as that of the active principles content on the rheological behavior, by setting the dependence between the shear stress $\tau$ and the shear rate $\dot{\gamma}$. The analysis of this dependence demonstrates that these emulsions present non-Newtonian behavior. The oxidation stability was monitored for 210 days by determining the peroxide value and the presence of initial and final oxidation products (by monitoring $\mathrm{K}_{232}$ and $\mathrm{K}_{270}$ values, respectively).
\end{abstract}

Keywords: cosmetic emulsions, emulsifier, mathematical models, oxidation, rheological behavior, stability, viscosity, peroxide value

\section{INTRODUCTION}

Emulsions are thermodynamically unstable colloidal systems, in which there are droplets of a liquid dispersed in a second immiscible fluid [1].Oil-in-water emulsions (O/W) are characterized by oil droplets dispersed in an aqueous continuous phase and are commonly used in various industrial applications, such as in food industry, pharmaceutical or cosmetic fields [2,3]. Cosmetics are more or less complex, stable and homogeneous mixtures, resulting from a formulation which consists in the association of a raw material with another one. These ingredients are subdivided into three categories: active principles, excipients and additives [4].

The use of bioactive extracts from a variety of botanicals in cosmetics accomplishes two functions: care of the body and as ingredients to influence the biological functions of the skin, providing the nutrients for healthy skin [5]. They possess various properties like photoprotection, antioxidant (vitamin C and $\mathrm{E}$, tea polyphenols, resveratrol, pomegranate fruit extract), antiaging

a Politehnica University Timisoara, Faculty of Industrial Chemistry and Environmental Engineering, 6 V. Pârvan Bd., RO-300223, Timisoara, Romania;

* Corresponding author: andra.tamas@upt.ro 
(oleanolic extract, boswellia), moisturizing (retinoids, alpha hydroxy acids, soy extract, aloe vera), astringent (arnica, cucumber), anti-irritant (coriander seed oil) antimicrobial activity [6] and anti-cellulite properties (caffeine) [7].

In order to obtain acceptable emulsions for cosmetic products, must be taken into account the incorporation of stabilizers (co-emulsifiers) to prolong storage stability, the selection of an effective preservation system to prevent their microbiological deterioration, as well as the introduction of other control substances (antioxidants, $\mathrm{pH}$ adjusters, thickening agents) [8].

Cosmetic emulsions can present instability during the storage, from chemical changes of the components, the presence of microorganisms or physical changes (mechanical or visual). The first two causes of instability are generally unacceptable.

In general, rheology is defined as a science that studies the interdependence between mechanical stress, the response of bodies and their properties. It establishes a series of mathematical models that describe the behavior of bodies subjected to stress, behavior determined by the dependence that exists between force (stress) and response (deformation, flow) [9].

Creams are semi-solid emulsions which contain mixtures of oil and water. Their consistency varies between liquids and solids. For this reason, the rheological characterization is more complicated because both rheological models for solids and those for liquids must be considered.

In cosmetic emulsions, rheological characterization is very important to ensure not only the flow control but also its absence when necessary. Thus, a cream must recover its structure and initial viscosity after being applied to the skin, without allowing it to flow or drip.

Also, rheological measurements are very useful to characterize the flow properties of emulsion systems and to predict their behavior during manufacturing, packing or final use [2].

The aim of this work is to analyse the rheological behavior of O/W emulsions. The influence of active principles content, the preparation temperature and the cooling rate were followed. The mathematical models which described the dependence $\tau=f(\dot{\gamma})$ were established. Also, it was studied the oxidation stability in time, depending on storage conditions.

\section{RESULTS AND DISCUSSION}

\section{Rheological characterization}

The influence of temperature on the rheological behavior was determined for all the samples. In Figure 1, the dependence between the shear stress $\tau$ and the shear rate $\dot{\gamma}$ is shown for emulsion A, at three temperature values. 
It is observed that the dependencies between the shear stress and the shear rate are linear, with a non-zero intercept corresponding to a yield stress $\tau_{0} \neq 0$. This behaviour is characteristic of non-Newtonian fluids (plastic Bingham) $[10,11]$, which begin to flow only after the shear stress exceeds this threshold (critical value) [12].

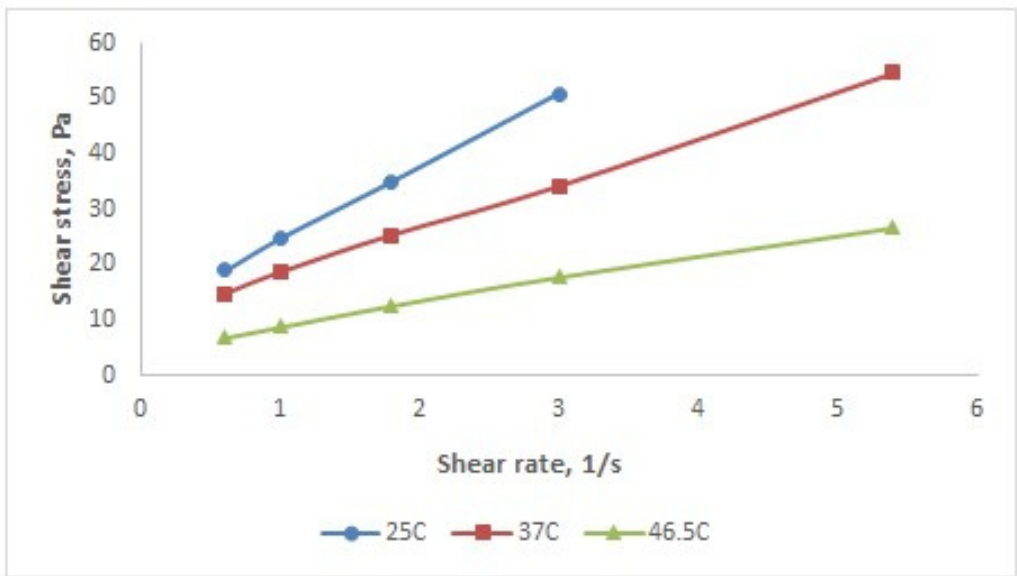

Figure 1. Shear stress $(\tau)$ vs. shear rate $(\dot{\gamma})$ for emulsion A

Using the TableCurve 2D program, the rheological equations corresponding to these dependences were established (Table 1), where $\eta_{p}$ is the Bingham plastic viscosity. The plastic viscosity is the slope of the straight line, so that it can be stated that Bingham fluid has an initial shear stress threshold followed by a Newtonian flow $[13,14]$.

Table 1. Rheological equations for emulsion $A$ (Bingham model)

\begin{tabular}{|c|c|c|}
\hline Temperature, ${ }^{\circ} \mathrm{C}$ & Eq. $\boldsymbol{\tau}=\boldsymbol{\tau}_{0}+\boldsymbol{\eta}_{\boldsymbol{p}} \cdot \dot{\boldsymbol{\gamma}}$ & $\mathrm{R}^{2}$ \\
\hline 25 & $\tau=11.17+13.24 \cdot \dot{\gamma}$ & 0.99969 \\
\hline 37 & $\tau=9.98+8.23 \cdot \dot{\gamma}$ & 0.99927 \\
\hline 46.5 & $\tau=4.81+4.11 \cdot \dot{\gamma}$ & 0.99651 \\
\hline
\end{tabular}

It is found that increasing the temperature leads to both decreasing the yield stress $\left(\tau_{0}\right)$ and plastic viscosity $\left(\eta_{p}\right)$, without changing the type of rheological behavior.

Because the curves $\tau=f(\dot{\gamma})$ obtained for emulsions $\mathrm{B}, \mathrm{C}$ and $\mathrm{D}$ have a slightly different shape from the curves obtained for emulsion $A$, the rheological equations were deduced using both the Bingham model (Table 2) 
and the Herschel-Bulkley model (Table 3 ). It is observed that they differ in the value of the flow index ( $n$ ) which is equal to 1 for Bingham fluids and has subunit values in the case of Herschel-Bulkley model. In this latest model, $k$ represents the consistency factor [11].

Table 2. Rheological equations for emulsions $B, C$ and $D$ (Bingham model)

\begin{tabular}{|c|c|c|c|}
\hline \multirow{2}{*}{ Em. } & \multicolumn{3}{|c|}{ Temperature, ${ }^{\circ} \mathrm{C}$} \\
\cline { 2 - 4 } & 25 & \multicolumn{3}{|c|}{37} & 46.5 \\
\cline { 2 - 4 } & \multicolumn{3}{|c|}{ Eq. $\boldsymbol{\tau}=\boldsymbol{\tau}_{0}+\boldsymbol{\eta}_{\boldsymbol{p}} \cdot \dot{\gamma}$} \\
\hline $\mathrm{B}$ & $\begin{array}{c}\tau=17.3+1.49 \cdot \dot{\gamma} \\
\left(\mathrm{R}^{2}=0.96868\right)\end{array}$ & $\begin{array}{c}\tau=9.74+0.61 \cdot \dot{\gamma} \\
\left(\mathrm{R}^{2}=0.94597\right)\end{array}$ & $\begin{array}{c}\tau=4.25+0.27 \cdot \dot{\gamma} \\
\left(\mathrm{R}^{2}=0.88417\right)\end{array}$ \\
\hline $\mathrm{C}$ & $\begin{array}{c}\tau=9.46+13.61 \cdot \dot{\gamma} \\
\left(\mathrm{R}^{2}=0.99495\right)\end{array}$ & $\begin{array}{c}\tau=5.15+6.35 \cdot \dot{\gamma} \\
\left(\mathrm{R}^{2}=0.99585\right)\end{array}$ & $\begin{array}{c}\tau=2.31+0.75 \cdot \dot{\gamma} \\
\left(\mathrm{R}^{2}=0.9657\right)\end{array}$ \\
\hline $\mathrm{D}$ & $\begin{array}{c}\tau=20.9+6.56 \cdot \dot{\gamma} \\
\left(\mathrm{R}^{2}=0.98489\right)\end{array}$ & $\begin{array}{c}\tau=11.48+3.6 \cdot \dot{\gamma} \\
\left(\mathrm{R}^{2}=0.9528\right)\end{array}$ & $\begin{array}{c}\tau=3.59+0.7 \cdot \dot{\gamma} \\
\left(\mathrm{R}^{2}=0.97074\right)\end{array}$ \\
\hline
\end{tabular}

Table 3. Rheological equations for emulsions $B, C$ and $D$ (Herschel-Bulkley model)

\begin{tabular}{|c|c|c|c|}
\hline \multirow{3}{*}{ Em. } & \multicolumn{3}{|c|}{ Temperature, ${ }^{\circ} \mathrm{C}$} \\
\hline & 25 & 37 & 46.5 \\
\hline & \multicolumn{3}{|c|}{ Eq. $\boldsymbol{\tau}=\boldsymbol{\tau}_{0}+\boldsymbol{k} \cdot \dot{\gamma}^{n}$} \\
\hline B & $\begin{array}{c}\tau=13.08+5.29 \cdot \dot{\gamma}^{0.582} \\
\left(\mathrm{R}^{2}=0.99877\right)\end{array}$ & $\begin{array}{c}\tau=5.92+3.80 \cdot \dot{\gamma}^{0.485} \\
\left(\mathrm{R}^{2}=0.99954\right)\end{array}$ & $\begin{array}{c}\tau=0.04+4.14 \cdot \dot{\gamma}^{0.283} \\
\left(R^{2}=0.88417\right)\end{array}$ \\
\hline C & $\begin{array}{c}\tau=8.15+15 \cdot \dot{\gamma}^{0.937} \\
\left(\mathrm{R}^{2}=0.9951\right)\end{array}$ & $\begin{array}{c}\tau=2.56+8.87 \cdot \dot{\gamma}^{0.838} \\
\left(\mathrm{R}^{2}=0.9979\right)\end{array}$ & $\begin{array}{c}\tau=0.215+2.64 \cdot \dot{\gamma}^{0.585} \\
\left(\mathrm{R}^{2}=0.99481\right)\end{array}$ \\
\hline D & $\begin{array}{c}\tau=9.17+18.75 \cdot \dot{\gamma}^{0.454} \\
\left(R^{2}=0.99799\right)\end{array}$ & $\begin{array}{c}\tau=0.023+15.23 \cdot \dot{\gamma}^{0.399} \\
\left(R^{2}=0.99711\right)\end{array}$ & $\begin{array}{c}\tau=1.39+2.48 \cdot \dot{\gamma}^{0.594} \\
\left(\mathrm{R}^{2}=0.99336\right)\end{array}$ \\
\hline
\end{tabular}

Bingham fluids do not have a constant viscosity but require a certain minimum value of the shear stress to initiate flow. The apparent viscosity $\eta_{a}$ depends on the shear rate (rel.1), more exactly it decreases with shear rate increasing. As the shear rate tends to infinity, the viscosity reaches the limit value - the plastic viscosity $\eta_{p}$ :

$$
\frac{\tau}{\dot{\gamma}}=\eta_{a}=\frac{\tau_{0}}{\dot{\gamma}}+\eta_{p}
$$

Thus, at $37^{\circ} \mathrm{C}$, the variation of the apparent viscosity as a function of the shear rate for these four emulsions is presented in Figure 2. It is observed that in the case of most viscous emulsions ( $C$ and $D$ ), due to the limitation of the viscosity range which can be determined by the device, the constant viscosity level $\left(n_{p}\right)$ has not be reached.

Figure 3, comparatively shows the dependence $\tau=f(\dot{\gamma})$ for emulsion $A$ (without the addition of active principles) and emulsion $B$ (with the addition of $10 \%$ active ingredients), at two temperature values. It is observed that, at the same temperature, emulsion B has lower shear stress values than 
emulsion $A$. This is also confirmed by the values of the yield stress and, respectively, plastic viscosity, which are lower in the case of emulsion $B$ (Table 1 and 2).

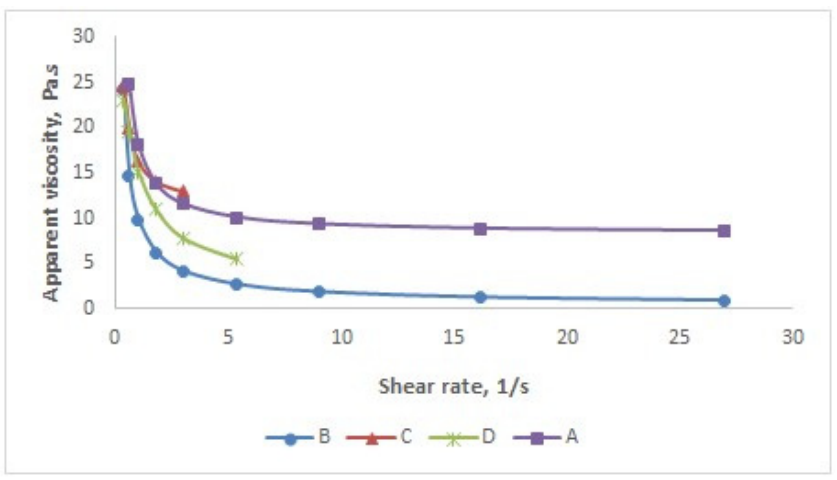

Figure 2. Apparent viscosity $\left(\eta_{a}\right)$ vs. shear rate $(\dot{\gamma})$ for emulsions $\mathrm{A}, \mathrm{B}, \mathrm{C}$ and $\mathrm{D}$ at $37^{\circ} \mathrm{C}$

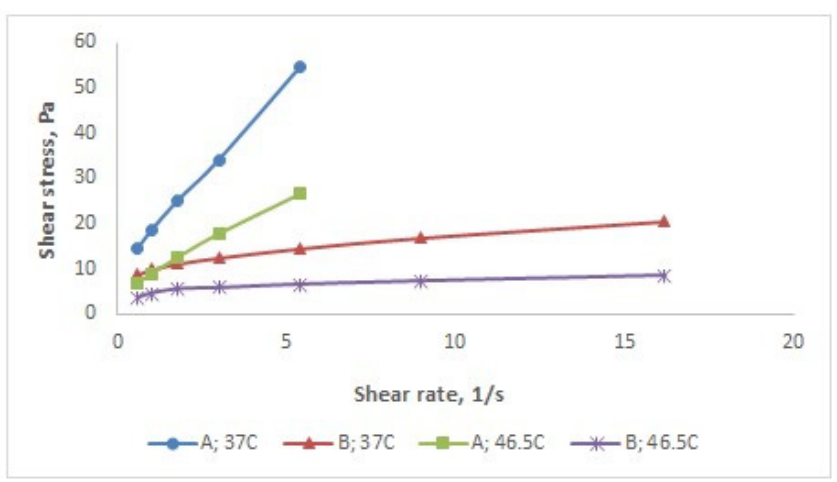

Figure 3. Shear stress $(\tau)$ vs. shear rate $(\dot{\gamma})$ for emulsions A and B

In order to establish the influence of the preparation temperature on the rheological behavior, emulsions with the same composition obtained at $70^{\circ} \mathrm{C}(\mathrm{B})$ and, respectively, at $90^{\circ} \mathrm{C}(\mathrm{C})$ were analysed. The dependence $\tau=f(\dot{\gamma})$, at two temperature values, is presented in Figure 4.

It is observed that the emulsion prepared at a higher temperature (emulsion $\mathrm{C}, 90^{\circ} \mathrm{C}$ ) has, at the same value of the temperature at which the measurement was performed, higher values of the shear stress compared to the emulsion prepared at $70^{\circ} \mathrm{C}(\mathrm{B})$. This observation is also supported by the higher values of both the consistency factor $(k)$ and the flow index $(n)$ for the emulsion C (Table 3). 


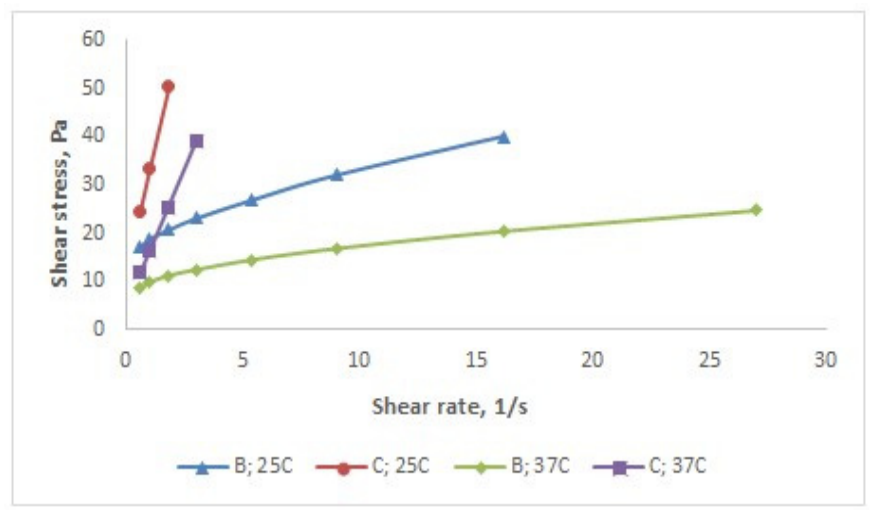

Figure 4. Shear stress $(\tau)$ vs. shear rate $(\dot{\gamma})$ for emulsions B and C

In order to establish the influence of the cooling rate on the rheological behavior, emulsions with identical composition were analysed: one of them was prepared at $70^{\circ} \mathrm{C}$ and then was cooled slowly, in air, to $40^{\circ} \mathrm{C}$ under continuous homogenization (emulsion $\mathrm{B}$ ), and the other one was suddenly cooled from $70^{\circ} \mathrm{C}$ to $40^{\circ} \mathrm{C}$ in ice water (emulsion D). The variation of the apparent viscosity as a function of the shear rate for these emulsions is shown in Figure 5.

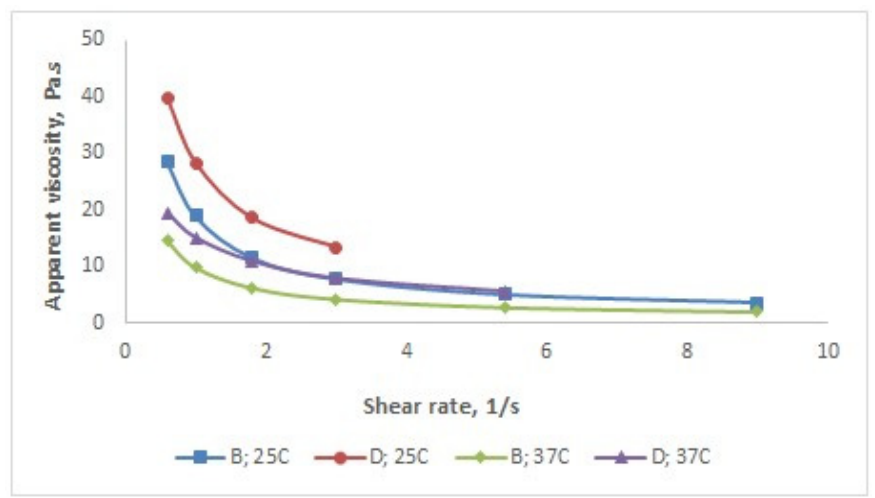

Figure 5. Apparent viscosity $\left(\eta_{a}\right)$ vs. shear rate $(\dot{\gamma})$ for emulsions $B$ and $D$

It is found that, at the same value of the shear rate and the same temperature, the values of the apparent viscosity are higher in the case of the suddenly cooled emulsion (D). 


\section{The oxidation stability}

The oxidation stability of the emulsions was studied by determining the peroxide value (PV) and UV absorbances at $232 \mathrm{~nm}$ and $270 \mathrm{~nm}$, respectively $\left(\mathrm{K}_{232} ; \mathrm{K}_{270}\right)$ for 210 days. Peroxide value is a parameter that gives the peroxides and hydroperoxides quantity formed in the first stage of oil oxidation [15]. These values are influenced by unsaturation degree of the oils, their storage conditions, temperature, light, air contact and the presence of some compounds with catalytic activity for oxidation [16]. $\mathrm{K}_{232}$ is related to the presence of hydroperoxides, conjugated dienes, carboxylic compounds and conjugated trienes. $\mathrm{K}_{270}$ is dependent on the secondary products formed from the oxidation products detected at 232nm [17].

The peroxide values of the emulsions exposed to air (A1-D1), slowly increased in the first period (180 days); after that, the increase becomes higher (Figure 6). These variations of the peroxide value demonstrate autocatalytic feature of the primary oxidation.

In the case of the emulsions that were not exposed to air (A-D), the curves PV vs. time are approximately horizontal (Figure 7). This is confirmed by the lack of the primary oxidation during the study. Comparatively, the peroxide value variation with time for $\mathrm{B}$ and $\mathrm{B} 1$ emulsions in the absence, respectively in the presence of the air is presented in Figure 8 . The increase of the peroxide value due to air exposure was of $200 \%$ comparatively to that without air contact, at the end of the study.

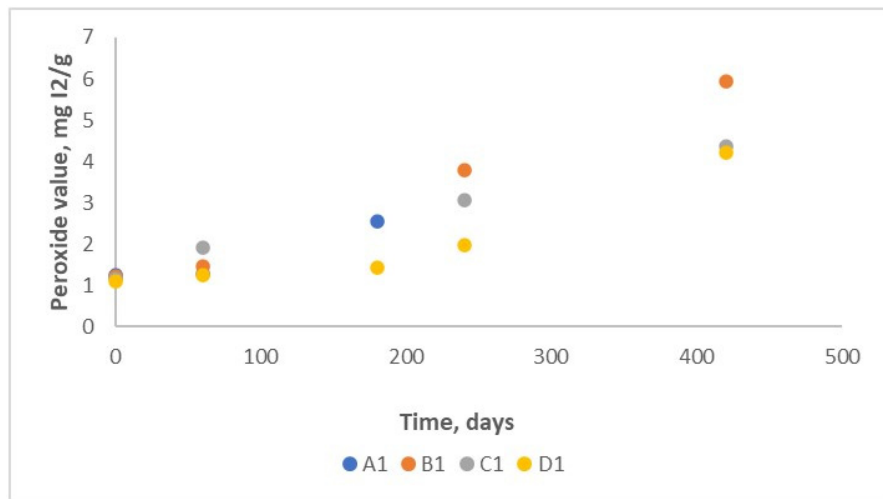

Figure 6. Peroxide value vs. time for emulsions A1-D1 


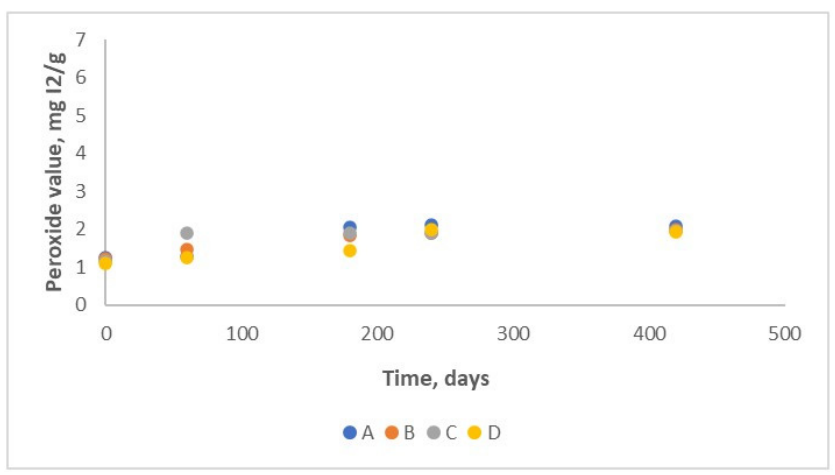

Figure 7. Peroxide value vs. time for emulsions A-D

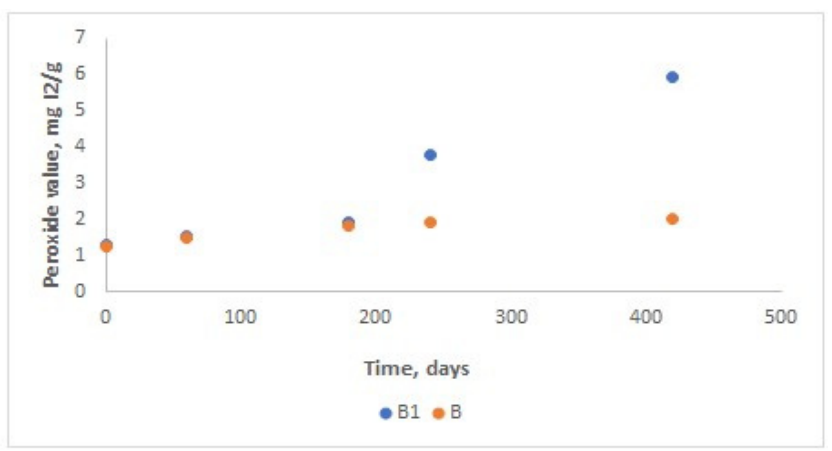

Figure 8. Peroxide value vs. time for emulsions $\mathrm{B}$ and $\mathrm{B} 1$

For the emulsions that have not come into contact with air, $\mathrm{K}_{232}$ and $\mathrm{K}_{270}$ remained at approximately constant values throughout the study period (Figures 9 and 10). This indicates the absence of secondary oxidation processes in the oil phase.

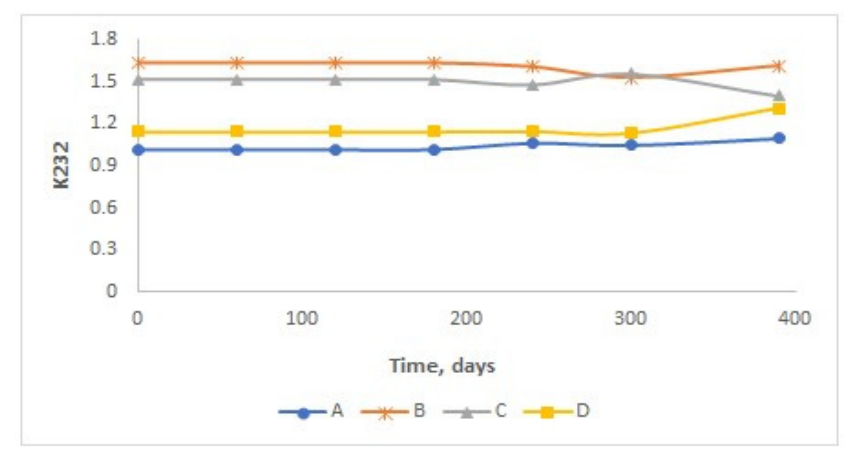

Figure 9. Spectrophotometric constant $\mathrm{K}_{232}$ for emulsions $\mathrm{A}-\mathrm{D}$ 
THE STUDY OF THE RHEOLOGICAL BEHAVIOR AND THE OXIDATION STABILITY OF SOME ...

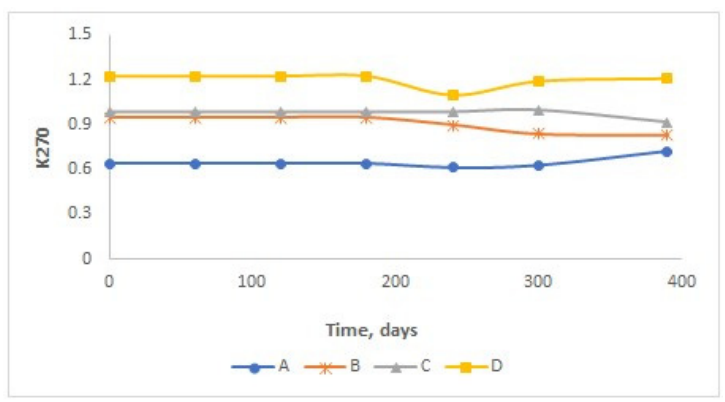

Figure 10. Spectrophotometric constant $K_{270}$ for emulsions A-D

For the emulsions exposed to air contact, the $\mathrm{K}_{232}$ absorbance had constant values for approximately 200 days; after that, they recorded an increase. Variation of $\mathrm{K}_{270}$ was significantly reduced comparatively to $\mathrm{K}_{232}$.

For the emulsions $\mathrm{B}$ and $\mathrm{B} 1$, in the absence, respectively in the presence of air, $K_{232}$ and $K_{270}$ variation during the study period is presented in Figures 11 and 12. According to these graphics, the secondary oxidation products are formed after 250 days.

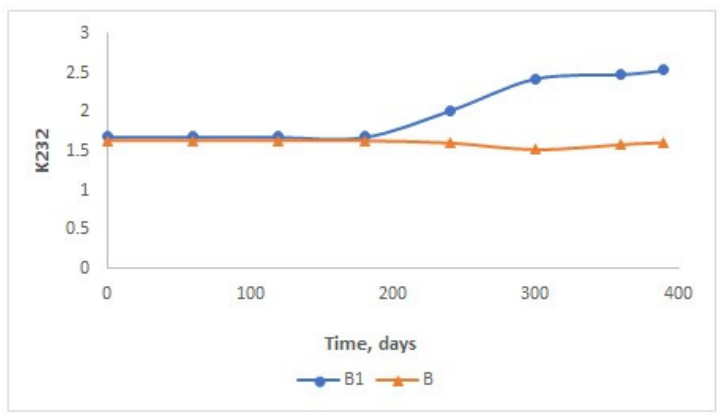

Figure 11. Spectrophotometric constant $K_{232}$ for emulsions $B$ and $B 1$

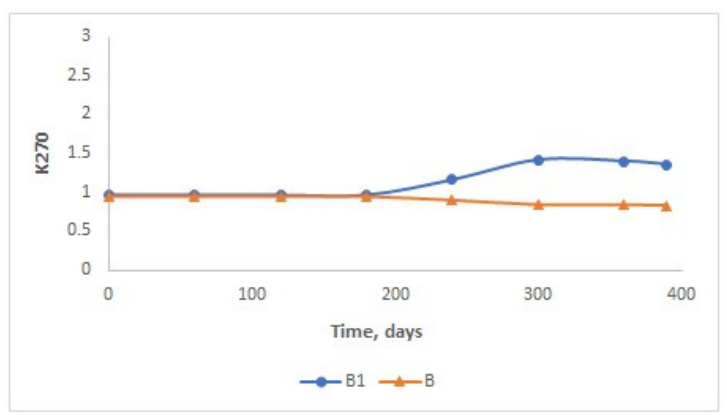

Figure 12. Spectrophotometric constant $K_{270}$ for emulsions $B$ and $B 1$ 


\section{CONCLUSIONS}

The experimental results show that the rheological properties of the analysed emulsions are determined by the preparation conditions (temperature and cooling rate), by the temperature at which the measurements are made, as well as the presence in the composition of the active principles.

All the four emulsions show non-Newtonian behavior with yield stress and the obtained rheological equations fit into the Herschel-Burkley and/or Bingham mathematical models.

In the case of Bingham model, the values of the yield stress $\left(\tau_{0}\right)$ and of the plastic viscosity $\left(\eta_{p}\right)$ decrease with increasing temperature. In the case of Herschel-Bulkley model, the yield stress varies similarly and the values of the consistency factor $(k)$ are correlated with those of the flow index $(n)$.

The decrease in the viscosity of the emulsions with active principles content in the aqueous phase is generated by the nature and concentration of the four incorporated active ingredients, the percentage of aqueous phase being the same in both emulsions.

The increase in the viscosity of the emulsion $C$ could be the consequence of the partial evaporation of the aqueous phase due to the higher temperature at which it was prepared.

Regarding the maintenance of the stability and quality of cosmetic emulsions, it is extremely important the control of their storage conditions (temperature, light, humidity, etc). Evaluation of $K_{232}$ and $K_{270}$ values and peroxide value, respectively, are simple and accurate methods to predict the quality and oxidation stability of different compounds with oily phase content.

Properly preserved cosmetic emulsions, when not exposed to air, were shown to have high oxidation stability for the entire period of the study (420 days). There was no change in the peroxide value, $K_{232}$ and $K_{270}$ values, which indicate the absence of the primary oxidation and the lack of the secondary oxidation products.

The emulsions that were exposed to air, did not suffer any oxidation during the first 200 days. The increase of the peroxide value within the second period, indicates oxidation processes in the oily phase. Nevertheless, these values are relatively low, under $7 \mathrm{mg} \mathrm{I}_{2} / \mathrm{g}$.

The values $K_{232}$ and $K_{270}$ for the samples exposed to air, increased moderately after 250 days. This increase confirms small quantities of secondary oxidation products. 


\section{EXPERIMENTAL SECTION}

\section{Preparation of the emulsions}

Both the oily phase (1) and the aqueous phase (2) are heated to $70^{\circ} \mathrm{C}$ (for emulsions $\mathrm{A}, \mathrm{B}$ and $\mathrm{D}$ ) and, respectively, to $90^{\circ} \mathrm{C}$ (for emulsion $\mathrm{C}$ ). Then, phase (1) was added over phase (2) and mixed for 10 minutes with a Lab High-shear Homogenizer, at 10000 rpm. After homogenization, emulsions A, $B$ and $C$ are gradually cooled to $40^{\circ} \mathrm{C}$, in air, under slower stirring (5000 rpm), and emulsion $D$ is suddenly cooled in ice water to the same temperature.

After reaching the temperature of $40^{\circ} \mathrm{C}$, the active principles, phase (3), are added (in emulsions B, C and D). The active principle consists of: a) Lactobacillus ferment lysate filtrate - probiotic used in anti-aging creams; b) tea tree leaf extract (Camellia Sinensis); c) pomegranate extract (Punica Granatum); d) caffeine.

The composition of the studied emulsions is presented in Table 4.

Table 4. The composition of the analysed samples

\begin{tabular}{|c|c|c|c|c|}
\hline \multirow[t]{2}{*}{ Ingredients } & \multicolumn{4}{|c|}{ Composition, wt \% } \\
\hline & \multirow[t]{2}{*}{$\mathbf{A}$} & \multirow[t]{2}{*}{ B } & \multirow[t]{2}{*}{ C } & \multirow[t]{2}{*}{$\mathbf{D}$} \\
\hline $\begin{array}{l}\text { Oily phase (1) } \\
\end{array}$ & & & & \\
\hline Non-ionic emulsifier & 5 & 5 & 5 & 5 \\
\hline Coco-Caprylate/Caprate (emollient / moisturizer) & 10 & 10 & 10 & 10 \\
\hline $\begin{array}{l}\text { Mixture of oils (sunflower, soybeans, olives, grape } \\
\text { seeds) }\end{array}$ & 4 & 4 & 4 & 4 \\
\hline Shea butter & 5 & 5 & 5 & 5 \\
\hline Cocoa butter & 4 & 4 & 4 & 4 \\
\hline Cetostearyl alcohol & 2 & 2 & 2 & 2 \\
\hline Preservative & 1.2 & 1.2 & 1.2 & 1.2 \\
\hline \multicolumn{5}{|l|}{ Aqueous phase (2) } \\
\hline Glycerol & 4 & 4 & 4 & 4 \\
\hline Sodium benzoate & 0.4 & 0.4 & 0.4 & 0.4 \\
\hline Distilled water & 64.4 & 54.4 & 54.4 & 54.4 \\
\hline \multicolumn{5}{|l|}{ Phase (3) } \\
\hline Active principles & - & 10 & 10 & 10 \\
\hline
\end{tabular}

\section{Rheological characterization}

The experimental determinations for rheological characterization of the samples were carried out under thermostatic conditions (temperature range $25 \div 50^{\circ} \mathrm{C}$ ), using a rotation viscometer Rheotest- 2 with the system vatdrum $S / S 3$, suitable for the viscosity range of these fluids and higher sensibility. The device allows the measurement of the torsion moment appeared thanks to the ring-shaped substance layer placed between a fixed cylinder and a rotating one with known revolution. The torsion moment is correlated with the shear rate. 
Shear rate values were changed in the range $0.333 \div 27 \mathrm{~s}^{-1}$.

\section{Determination of peroxide value}

The peroxide value was determined according to $[16,18]$ : the sample (approximately $1 \mathrm{~g})$ is treated with a glacial acetic acid-chloroform $(3: 2, \mathrm{v} / \mathrm{v})$ solution and then with a solution of $\mathrm{KI}$. It was kept in the dark for 5 minutes followed by the titration with a standard solution of sodium thiosulfate $0.1 \mathrm{~N}$ using starch as indicator.

\section{Determination of Specific UV Extinction Coefficients $\left(K_{232}\right.$ and $\left.K_{270}\right)$}

The measurement was performed through UV/VIS spectrophotometry with a UV/VIS Cary 60-Agilent Technologies spectrophotometer. Spectrophotometric analysis of the emulsions was performed in accordance with [17], which involves the determination of the specific extinction in cyclohexane at wavelength of 232 and $270 \mathrm{~nm}$ and the determination of the extinction coefficients $\mathrm{K}_{232}$ and $\mathrm{K}_{270}$.

A mass of $0.25-0.3 \mathrm{~g}$ emulsion was weighted and dilluted to $1 \%$ in cyclohexane. Absorbance values were measured using a $1 \mathrm{~cm}$ path length quartz cell at wavelength of 232 and $270 \mathrm{~nm}$. The extinction coefficients $\left(K_{\lambda}\right)$ were calculated in accordance with Lambert-Beer law.

\section{REFERENCES}

1. F. Calvo; J.M.Gomez; L. Ricardez-Sandoval; O. Alvarez; Chem.Eng.Res.Des., 2020, 161, 279-303

2. L. Gilbert; C.Picard; G. Savary; M. Grisel; Colloids Surf., A, 2013, 421, 150-163

3. P. Dubuisson; C.Picard: M. Grisel;G. Savary; Colloids Surf., A, 2018, 536, 38-46

4. J-B. Guillerme; C. Couteau; L. Coiffard; Cosmetics, 2017; 4(3), 35-49

5. A.S. Ribeiro; M. Estanquiro; M.B. Oliveira; J.M.S. Lobo; Cosmetics, 2015, 2, 48-65

6. D. Chanchal; S.Swarnlata; J.Cosmet.Dermatol., 2008, 7, 89-95

7. A. Herman; A.P.Herman; Skin Pharmacol Physiol, 2013, 26, 8-14

8. K. Sakamoto; R.Lochhead; H.Maibach; Y.Yamashita; Cosmetic Science and Technology: Theoretical Principles and Applications, $1^{\text {st }}$ ed.; Elsevier, 2017; pp.499-502

9. B. Ratner, A. Hoffman, F. Schoen, J. Lemons; Biomaterials Science: An introduction to Materials in Medicine, $2^{\text {nd }}$ ed., Academic Press, 2004, 23-31.

10. G. Schramm; A Practical Approach to Rheology and Rheometry, $2^{\text {nd }}$ ed.; Thermo Electron Karlsruhe, 2004; pp.15-30

11. A. Miclăuș; V. Pode; Cazuri particulare de curgere a fluidelor ideale și reale. Elemente de reologie, Ed. Casa Cărții de Știintă, Cluj-Napoca, 2018, pp.48-56 
12. B.T. Zengeni; Bingham Yield Stress and Bingham Plastic Viscosity of Homogeneous non-Newtonian Slurries; Dissertation-Cape Peninsula University of Technology, 2016, pp.9-22

13. H.F. George; F. Qureshi; Newton's law of viscosity, Newtonian and nonNewtonian fluids, in Encyclopedia of Tribology, Q.J. Wang, Y.W. Chung Eds.; Springer Science+Business Media, NY, 2013, pp.2419-2424

14. R. Caenn; H.C.H. Darley; G.R. Gray; The rheology of drilling fluids, in Composition and properties of drilling and completion fluids, $6^{\text {th }}$ ed; Gulf Professional Publishing, 2011, Chapter 5, pp.183-185

15. E. Choe; D.B. Min; Compr. Rev. Food Sci. Food Saf., 2006, 5, 169-186

16. M. Popa; I. Glevitzky; G-A. Dumitrel; M. Glevitzky; D. Popa; Sci. Papers Ser. E, 2017, VI, 137-140

17. A. Malvis; P. Simon; T. Dubaj; A. Sladkova; A. Haz et al.; Hindawi J.Chem., 2019, Article ID 4567973

18. Official Methods of Analysis of AOAC International, edited by P. Cunniff, $16^{\text {th }}$ ed., AOAC International, Arlington, 1995, Method 965.33. 
